\title{
Digital entrepreneurship ecosystem as a new form of organizing: the case of Zhongguancun
}

\author{
Wenjie Li, Wenyu Du ${ }^{*}$ and Jiamin Yin
}

\author{
* Correspondence: \\ duwenyu@rbs.ruc.edu.cn \\ Department of Management \\ Science, School of Business, Renmin \\ University of China, Beijing 100872, \\ China
}

\begin{abstract}
Digital innovation is becoming increasingly important in today's economy. Many digital innovations are developed not within organizations, but in innovation-driven entrepreneurial ecosystems, where various entrepreneurship related stakeholders collaborate and cooperate. Despite its significance, studies on digital entrepreneurship ecosystems (DEEs) are limited and the concept is largely undertheorized. This study intends to fill that gap by studying how a DEE organizes. This organizing issue is challenging, because stakeholders of a DEE are self-organizing and are not governed by any formal authority. To answer that question, we adopt forms of organizing as a theoretical lens, which provides structure to examine organizing issues. Through an in-depth case study of Zhongguancun, the Silicon Valley of China, we unveil eight processes around the themes of division of labor and integration of efforts. We further show that the forms of organizing feature a balance of centralized design and de-centralized emergence. This balanced view extends the forms of organizing literature, which takes an either/or perspective. Ecosystem architects and policy makers who intend to build entrepreneurship ecosystems to promote local economies can derive practical implications from our findings.
\end{abstract}

Keywords: Digital entrepreneurship ecosystem, New forms of organizing, Case study

\section{Introduction}

Digital innovation often takes place outside the boundary of firms through collective collaboration, which overcomes the resource limitations of a single firm (Adner and Kapoor, 2010). Thus, we need to treat digital innovations at the ecosystem level, which could provide a platform to aggregate various resources and facilitate such collaboration (Lindgren et al., 2008). In practice, digital entrepreneurship ecosystems (DEE) have already been shown to accelerate start-ups based on digital innovations. A well-known example is Silicon Valley. Many regions, such as London, Berlin, Paris, Tel Aviv in Israel, and Singapore, have also started to build DEEs to revive local economies (Herrmann et al., 2015; Roth et al. 2015; Yip, 2015).

Digital entrepreneurship ecosystems (DEE) play an important role as accelerators for creating digital start-ups. However, extant studies on digital innovation mainly focus on organization-level analysis (Bharadwaj et al., 2013; Sambamurthy et al., 2003; Yoo et al., 2010), whereas studies at the ecosystem level are limited. This hampers our 
understanding of DEEs (Shen et al. 2015). Meanwhile, the concept of entrepreneurial ecosystems remains underdeveloped. The term ecosystem is widely used to explain the birth-boom of entrepreneurship, but as a theoretical concept, entrepreneurial ecosystem is underdeveloped (Spigel, 2015). Due to this gap, the Strategic Entrepreneurship Journal (SEJ), launched a call for papers on entrepreneurial ecosystems in 2015 (Autio et al., 2015).

Traditional thinking about organizations is that organizations maintain a boundary, within which the transaction cost is lower than in the open market. But what really lowers the transaction cost is if that organization has clear information about the division of labor and the integration of efforts, the two fundamental elements of organization (Puranam et al., 2014). Compared with the open market, an ecosystem seems to be more efficient. Some scholars treat ecosystems as organizations (Gulati et al., 2012). Unlike a traditional organization, however, an ecosystem lacks the formal authority that is needed for coordination. Therefore, how an ecosystem achieves a division of labor and integration of effort is an interesting question. We refer to the division of labor and integration of efforts as organizing forms (Puranam et al., 2014). We posit that a healthy and productive digital entrepreneurship ecosystem possesses a relatively stable organizing form whereby its stakeholders can effectively achieve a division of labor and integration of effort, without a hub or a central authority, while an illorganized digital entrepreneurship ecosystem is bound to fail.

Contrary to traditional thinking about organizing, many DEEs can organize various actors without formal authority. Yet, the knowledge about "how does a DEE organize" is inadequate, posing a great knowledge gap for both scholars and practitioners. Different from traditional organizations, actors in a DEE do not share the same goal and are free to make decisions based on their own interests, which may lead to conflicts rather than collaborations. For example, actors may prefer to drain the value within an ecosystem to maximize their own benefits, rather than share it with other actors. Therefore, the details of the organizing processes that facilitate inter-organizational coordination and collaboration are worth exploring (Gulati et al., 2012).

Thus, our study aims to analyze a digital entrepreneurship ecosystem to answer the question of "how does a digital entrepreneurship ecosystem organize to support digital innovations?" To answer this question, we adopt the forms of organizing, as synthesized by Puranam et al. (2014) based on prior literature related to the forms of organizing, as a theoretical lens. Despite the different forms of organizing, they all address four universal problems: task division, task allocation, reward distribution and information flow. These four organizing problems are synthesized from the prior literature and they commonly exist in many forms of organizing, such as innovation networks, innovation clusters, ecosystems and self-organizing groups.

Since DEEs are different from traditional forms of organizing as they lack traditional organizing elements such as formal authority, the solutions to these four problems may be different and worthwhile exploring (Puranam et al., 2014). Thus, the organizing process of a DEE is relatively novel and we can treat a DEE as a "new" form of organizing. This theoretical lens enables us to analyze a DEE as an organization rather than a pure combination of actors. These universal problems of organizing provide us with an operational framework to analyze the organizing activities in DEEs. 
We conducted a case study on Zhongguancun (ZGC), a successful DEE known as the Silicon Valley of China. Analyzing data collected from 51 interviewees with high heterogeneity, we find 8 activities that contribute to the organizing form of this DEE. Our paper has three important contributions. First, we contribute to the digital innovation literature by extending the research from the individual or organizational level to an ecosystem level (Shen et al. 2015). This ecosystem level analysis is important, because a digital entrepreneurship ecosystem is conducive to digital innovation exploitation by aggregating various resources and facilitating inter-firm collaboration. Second, our paper makes contributions to the organizing form literature (Gulati et al., 2012; Puranam et al., 2014). The existing four-dimension theoretical framework takes an either/or perspective when it comes to choose between emergent or top-down organizing. Our findings based on this digital entrepreneurship ecosystem demonstrate that these two approaches are not contradictory and can coexist.

\section{Literature review}

\section{Digital innovation and digital entrepreneurship ecosystem (DEE)}

According to Per Yoo et al. (2010), digital innovation can be defined as the implementation of new combinations of digital and non-digital resources to produce novel products and processes. Because of the limited resources and knowledge available within individual firms, many firms seek to leverage external resources to generate digital innovations (Selander et al., 2010). Meanwhile, the collaboration networks of inter-firms (Schilling and Phelps, 2007) and the boundary-spanning practices (Lindgren et al., 2008) have significant effects on innovation. Thus, digital innovation typically involves multiple actors and interactions. In other words, ecosystems which contain various resources and information are important for digital innovation.

Innovation and entrepreneurship are often intertwined since many digital entrepreneurial ventures are based on digital innovation (Bessant and Tidd, 2007). Digital entrepreneurship is one stream of entrepreneurship. The unique characteristic of digital entrepreneurship, per Davidson et al. (2010), is that digital entrepreneurship consists of three interconnected types of entrepreneurship: business entrepreneurship, knowledge entrepreneurship and institutional entrepreneurship. Digital entrepreneurship is a multi-faceted phenomenon that contains all three types.

Business entrepreneurship is the type of entrepreneurship whereby new ventures are created. This is the most popular type of entrepreneurship in the literature. Knowledge entrepreneurship involves the pursuit of opportunities based on information and knowledge to create a domain-related knowledge base and pursue new ventures related to this knowledge base. Consultants, journalists and academics are examples of knowledge entrepreneurs. Institutional entrepreneurship can be defined as the activities of actors who have interest arrangements and who leverage resources to create new institutions or transform existing ones. For example, the rise of E-commerce platforms, such as Amazon and Alibaba, has created a new form of retail market, which is an institutional entrepreneurship.

These three types of entrepreneurship are not exclusive. Instead, they are reinforcing. Davidson et al. (2010) posit that a successful digital entrepreneurship should combine business, knowledge and institutional opportunities. For example, Alibaba Inc, an E- 
commerce company, is first a business enterprise, but at the same time, this enterprise contains important knowledge and institutional implications.

A digital entrepreneurship ecosystem is an ecosystem where digital entrepreneurship emerges and develops. Because an ecosystem can facilitate the integration of resources and supportive elements beyond the firm-level, a digital entrepreneurship ecosystem is important for the success of digital entrepreneurship (Spigel, 2015). If we treat digital entrepreneurship as characterized by individualism, we can then see a DEE, in which various resources and elements can be integrated to facilitate the process of digital entrepreneurship, as a kind of collectivism. Another related concept is "digital ecosystem", or "digital business ecosystem". Per Corallo et al. 2007, a digital ecosystem is defined as the ICT enabling infrastructure that supports the cooperation, the knowledge sharing and the building of a business ecosystem. A digital business ecosystem is based on digital business, while a digital entrepreneurship ecosystem is based on digital entrepreneurship.

Corallo et al. (2007), expanding on the metaphor of natural ecosystems, separate the concepts of digital ecosystem and business ecosystem by its core species. A digital ecosystem is populated by digital species, while a business ecosystem is populated by business species. Similarly, a DEE is populated by digital species while an entrepreneurship ecosystem is populated by entrepreneurship species. This can be confirmed by the definition of digital entrepreneurship and other types of entrepreneurship. Digital entrepreneurship pursues opportunities based on the use of digital technologies, while others pursue opportunities based on business, knowledge or institutions (Davidson and Vaast 2010).

In summary, we can draw a picture to show the differences between entrepreneurship, entrepreneurship ecosystems, digital entrepreneurship and digital entrepreneurship ecosystems (Fig. 1). At the individual level, traditional entrepreneurs pursue opportunities based on business, knowledge or institutions, while digital entrepreneurs pursue digitallyenabled opportunities based on business, knowledge or institutions. After integrating resources beyond the firm-level, an ecosystem is formed at the collective level. At this level, the main difference between an entrepreneurship ecosystem and a digital entrepreneurship ecosystem is that a DEE is populated by digital species while an entrepreneurship ecosystem is populated by entrepreneurial species.

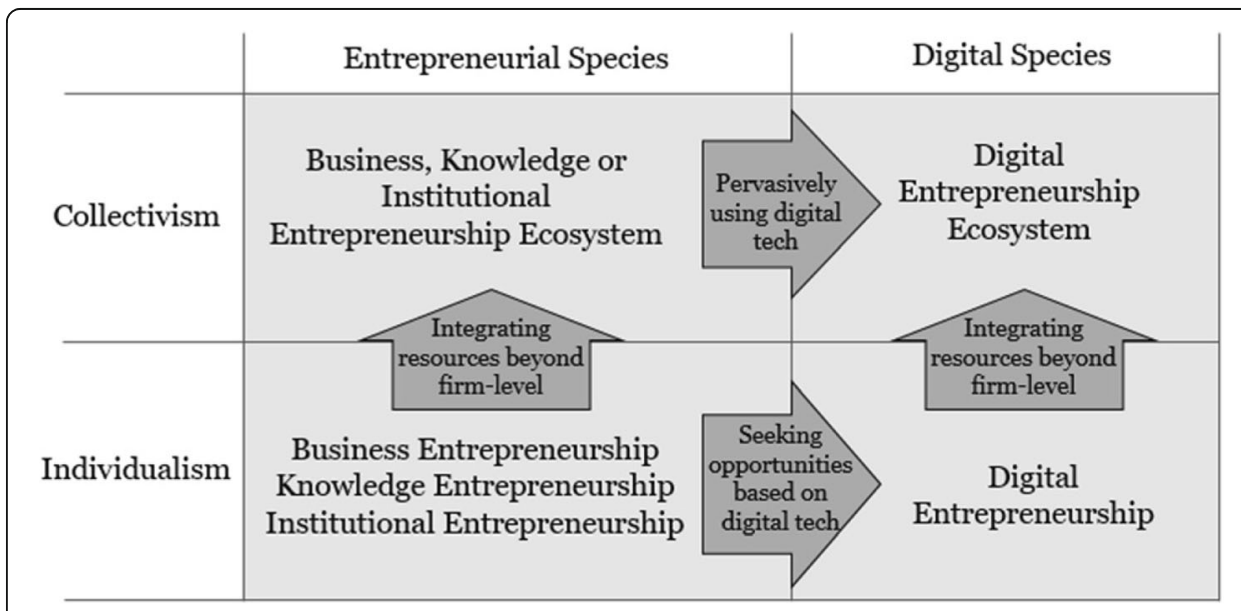

Fig. 1 DEE is a collectivist infrastructure populated by digital species 
However, studies on digital entrepreneurship at the ecosystem level are limited. Most studies focus on the individual and organizational level, in which entrepreneurial processes and context are the main research points (Shane and Venkataraman, 2000; Zahra et al., 2014; Biao and Dong, 2014; Yi et al., 2008). A macro scope is needed to understand the strategy of digital entrepreneurship (Spigel, 2015). Moreover, the academic research on entrepreneurship in China should be paid more attention to contribute knowledge and practical implications on Chinese entrepreneurship (Zhang et al., 2012). Therefore, we focus our research on a macro scope of entrepreneurship in Chinese context, that is the digital entrepreneurship ecosystem in ZGC.

To address the gap in the theorization of ecosystems, a tool or framework is needed to analyze the ecosystem (Autio et al., 2015; Spigel, 2015). Because agents within an ecosystem are legally independent entities, it is natural to consider an ecosystem as a multi-organizational problem, as most studies have done. Nonetheless, the concept of a "meta-organization", in which firms or individuals are not bound by formal authority based on employment relationships (Gulati et al., 2012), enables us to use this framework organization theory to analyze the ecosystem concept. To unveil the black box of a DEE's organizing process, we adopt the framework of forms of organizing. This will be discussed in detail in the next section.

\section{Forms of organizing}

After reviewing studies which cover a range of topics from innovation networks, to organizational design, to ecosystems and self-organization, Puranam et al. (2014) have noted that organizations, irrespective of their form, address two fundamental problems of organizing: the division of labor and the integration of effort. Puranam et al. (2014) further divide the problem of "division of labor" into task division and task allocation, and the problem of "integration of effort" into reward provision and information flow (summarized in Table 1).

Task division refers to the problem of mapping the goals of the organization into tasks and subtasks. It describes the problem of breaking down the system goal into contributory subtasks in organizations. In other words, it decides what jobs the system has. For task division, Puranam et al. (2014) argue that the following three principles should be relevant: excluding members that do not fit the system goal, no essential tasks remaining incomplete, and little redundancy among subtasks. These principles can be achieved by the initial design (MacCormack et al., 2006), the participation and contributing by members (Puranam et al., 2014), co-specialization of members (Thomas and Autio, 2012) and the transparency of task division (Baldwin and Clark, 2006).

Task allocation refers to the problems of mapping the tasks obtained through task division to individual agents (Puranam et al., 2014, p. 165). It describes the problem of allocating a job to the right agent. The commonly used mechanisms for task allocation are assignment (Hackman and Oldham, 1976) and self-selection based on capability, resources and preference (Puranam et al., 2014). The process of self-selection can be considered to be decisionmaking, which can be influenced by both internal and external factors. Competition is an external factor for an organization, but it is also a critical factor for a successful ecosystem (Moore, 1993; Peltoniemi and Vuori, 2004). Therefore, self-selection based on competition is also a major mechanism of task allocation. 
Table 1 Summary of forms of organizing

\begin{tabular}{|c|c|c|}
\hline $\begin{array}{l}\text { Fundamental } \\
\text { problems }\end{array}$ & Description & Example of solutions \\
\hline Task division & $\begin{array}{l}\text { The problem of mapping the goals of } \\
\text { the organization into tasks and subtasks. }\end{array}$ & $\begin{array}{l}\checkmark \text { Initial structure designed by founder } \\
\text { (MacCormack et al., 2006); } \\
\checkmark \text { Participation and contribution by other } \\
\text { members (Puranam et al., 2014); } \\
\checkmark \text { Transparency of task division (Baldwin } \\
\text { and Clark, 2006). }\end{array}$ \\
\hline Task allocation & $\begin{array}{l}\text { The problem of mapping the tasks } \\
\text { obtained through task division to } \\
\text { individual agents. }\end{array}$ & $\begin{array}{l}\checkmark \text { Assignment (Hackman and Oldham, 1976); } \\
\checkmark \text { Self-selection based on internal factors } \\
\quad \text { (Puranam et al., 2014); } \\
\checkmark \text { Self-selection based on external factors } \\
\text { such as competition (Moore, 1993). }\end{array}$ \\
\hline Reward distribution & $\begin{array}{l}\text { The problem of mapping a set of } \\
\text { rewards to the agents in the organization } \\
\text { and motivating the agents to cooperate. }\end{array}$ & $\begin{array}{l}\checkmark \text { Compensation (Prendergast, 1999); } \\
\checkmark \text { Intrinsic motivation (Hackman and } \\
\quad \text { Oldham, 1976); } \\
\checkmark \checkmark \text { Social norms (Shah, 2006); } \\
\checkmark \checkmark \text { Value creation (Thomas and Autio, 2012); } \\
\checkmark \checkmark \text { Culture as a tool kit (Spigel, 2015). }\end{array}$ \\
\hline Information flow & $\begin{array}{l}\text { The problem of ensuring that an } \\
\text { organization's agents have the } \\
\text { information needed to execute their } \\
\text { tasks and coordinate actions with others. }\end{array}$ & $\begin{array}{l}\checkmark \text { Physical collocation (Puranam et al., 2014); } \\
\checkmark \text { Virtual tools (Puranam et al., 2014); } \\
\checkmark \text { Conference (Garud, 2008). }\end{array}$ \\
\hline
\end{tabular}

The distribution of rewards refers to the problem of mapping a set of rewards to the agents in the organization-to motivate the agents to cooperate by taking costly actions toward executing the tasks they have been allocated (Puranam et al., 2014, p. 165). It mainly solves the problem of motivating agents to enter into and expend effort to achieve allocated tasks. Under the employment contract, compensation is the main mechanism of reward distribution (Prendergast, 1999). As to motivation, intrinsic motivation is also important for motivating employees to put effort into executing tasks (Hackman and Oldham, 1976), especially in the new forms of organizations where an employment contract is absent. The value logic of an ecosystem is that it provides agents in the ecosystem with opportunities to capture and co-create value (Thomas and Autio, 2012). This value creation attracts agents to join the ecosystem and ensures the fair distribution of rewards. Reward distribution can also be enhanced by social norms (Shah, 2006) and culture (Spigel, 2015; Swidler, 1986).

The information flow refers to the problem with ensuring that an organization's agents have the information needed to execute their tasks and coordinate actions with others (Puranam et al., 2014, p. 166). It constructs the linkages among agents to integrate their efforts. Physical collocation and virtual tools are the common solutions to achieving information flow (Puranam et al., 2014). In many communities, a conference plays a significant role as a prime venue for information exchange and interaction (Garud, 2008).

\section{Methodology}

The case research approach is adopted for the following reasons. First, because research approaches should follow the research questions (Walsham, 1995) and our main research question is a "how" question, a case study method is more appropriate (Eisenhardt, 1989). Second, as our study aims to explore our theoretical framework by rethinking an ecosystem as an organization, a case study is more appropriate for theory building (Siggelkow, 2007). 
Third, because a case study is suited for exploring complex phenomena (Yin, 2013) and how a large entrepreneurship ecosystem organizes itself is intricately embedded in the social context of the ecosystem, an in-depth case study is more suitable to understand this phenomenon.

We chose ZGC as our case target for the following reasons. First, ZGC is a typical DEE that is populated by digital species and integrates various resources beyond the firm-level. Heterogeneous members gather in ZGC to facilitate the development of digital entrepreneurship. Most activities in ZGC are related to entrepreneurship in the digital technology field and thus, ZGC is populated by digital species. Second, ZGC is a successful DEE in China and is a benchmark for entrepreneurship ecosystems. Many other provinces in China try to imitate its pattern to develop their local entrepreneurship ecosystems. Third, ZGC emerged in China where government has a strong influence in the economy, and plays an important role in the development of ZGC. The involvement of the government in the development of this entrepreneurial ecosystem is the key differentiating factor between Zhongguancun and DEEs in other regions of the world, such as the United States and Europe. Thus, the role of government, the architect of the DEE in Zhongguancun, is particularly interesting. Meanwhile, inspired by the success of Silicon Valley, many governments have started to follow suit and build their own DEEs. The case study of ZGC where government plays an important role may have valuable practical implications.

\section{The case setting}

The area occupied by the ZGC digital entrepreneurship ecosystem used to be a cluster of electronics markets and book stores. After 2010, the rise of E-commerce in China affected the business of the ZGC stores. Most were closed or transformed into other businesses. On Oct 2013, the Beijing municipal government announced a policy that a high-technology entrepreneurship cluster was to be built in Zhongguancun. Under this policy, the Haidian District government (where ZGC is located) started to transform ZGC into an ecosystem of high-technology entrepreneurship. With the principal of "guided by government, operated by market", many entrepreneurs and entrepreneurial service providers were involved. On June 2014, the ZGC entrepreneurship ecosystem was formally established and called "ZGC InnoWay (abbreviation of Innovation Way)".

ZGC InnoWay is a 200-meter long road, located in the core of Haidian District with convenient transportation. Many elite universities are located near ZGC InnoWay, including Tsinghua University, Peking University and Renmin University. One of China's most important research institutions and think tanks-the Chinese Academy of Sciencesis also located on the corner of the street. Almost every service that an entrepreneur needs to set up a business, such as financial services, government services, entrepreneurial training, human resource services, legal services etc. can also be found on this street.

In October 2015, to expand the available resources and integrate local services, an advanced ZGC entrepreneurship ecosystem was established with the help of the government. It is a 7.2-kilometer long street with intensive resources including higher education institutions, venture capital and enterprises. On the 200-meter InnoWay, on average every day, 2.2 events are held, 1.5 start-ups are financed, and average financing of about 7 million Yuan is provided. This is an outstanding performance for an entrepreneurship cluster and therefore, we posit that ZGC is a successful digital entrepreneurship ecosystem. 


\section{Data collection}

This study follows the interpretive case study methodology (Klein and Myers, 1999). Our analysis unit is the digital entrepreneurship ecosystem. There are three main phases in the research process for this study.

The first phase, starting in December 2014, consisted of preparation. In this phase, we collected and analyzed secondary data on ZGC and entrepreneurship development in China (for detailed information, refer to Appendix 1). Then we conducted interviews. We had the good fortune to interview the deputy head of the Zhongguancun Administrative Committee (ZAC). ZAC is a government agency in charge of the development and construction of ZGC. Later, interviews were conducted with some of the main accelerators. After analyzing the data, we developed a big picture about ZGC in the context of China's digital entrepreneurship boom. This analysis also revealed some details about the development of and relationships in ZGC. Organizations and individuals were independent in legal terms, which means that there was no employment relationship between them. This finding is also confirmed in the next phase of the study.

The second phase involved extensive data collection. It started in April 2015. In this phase, we conducted extensive semi-structured interviews in ZGC. After excluding some low-quality interviews (such as irrelevant interviews, and interviews stopped early due to external circumstances), 51 unique interviews were conducted. Interviewees included digital entrepreneurs, government officers, accelerator staff, venture capital investors, and service providers (for more information, refer to Appendix 2). Each interview lasted on average 50 minutes and was conducted by at least two researchers. These interviews yielded 472 pages of transcripts and notes. For a deeper understanding of ZGC, one of the researchers joined an accelerator as an intern for 4 months (from May to Aug 2015).

\section{Data analysis}

Data analysis started in Aug 2015. The techniques of open coding, axial coding and selective coding were used to systematically analyze the data (Corbin and Strauss, 1990). Open coding was used to identify major elements from the data, e.g., designing tasks assigning tasks, task self-selection, competition among members, preferring knowledge sharing, culture as an incentive, social norms to avoid free-riding and so on. Axial coding consists of identifying relationships among elements from open coding. For example, for preferring knowledge sharing, culture as an incentive and social norms to avoid free-riding, these open codes reflect the cultural attributes of a DEE so we summarized them as "entrepreneurial culture as a toolkit". Selective coding was based on the core variable we had previously identified -how does a DEE organize? Through our theoretical lens, we clustered the above codes into 8 key categories. This phase was conducted together with axial coding, and also involved intensive literature review so that findings could be supported by prior studies. During back and forth comparison between the literature and data, we changed some descriptions of codes from open coding and selective coding in order to match the literature and our core variables.

To ensure the reliability and validity of the data collection and analysis, the following methods were applied simultaneously (Summarized in Table 2). To achieve reliability in data collection, data were triangulated by interviewing various members of the ecosystem. 
Table 2 Methods to Ensure Reliability and Validity

\begin{tabular}{lc}
\hline Methods to Ensure Reliability & Methods to Ensure Validity \\
\hline$\checkmark$ Conducted semi-constructed interview and & $\checkmark$ At least two researchers involved in the process of \\
$\begin{array}{l}\text { adjusted questions based on interviewees } \\
\text { responses. }\end{array}$ & $\begin{array}{l}\text { interview: one asked questions while the other(s) took } \\
\text { notes and complemented questions, then compared } \\
\text { interpretations with each other. }\end{array}$ \\
$\begin{array}{l}\text { Data was collected in multiple ways in } \\
\text { Onder to ensure data can be triangulated. }\end{array}$ & $\checkmark$ The coding process also involved multiple researchers. \\
$\begin{array}{l}\text { to be supported by another interviewee or } \\
\text { archive data. }\end{array}$ & $\begin{array}{l}\text { Codes and descriptions were changed or adjusted } \\
\text { based on the common view of researchers. }\end{array}$ \\
$\begin{array}{l}\text { We studied China's entrepreneurship environment } \\
\text { and the development of ZGC beforehand, so that } \\
\text { interview design and data could be contextualized. }\end{array}$ & $\begin{array}{l}\text { We presented our findings to other scholars and } \\
\text { practitioners to get feedback and subsequently } \\
\text { enhance the validity of findings. }\end{array}$ \\
\hline
\end{tabular}

Combining secondary data (such as news, websites, and government documents) and interview data also enhanced the reliability of the data and findings. In order to achieve validity, as least two researchers were involved during both data collection and analysis. We presented our analyzing process and findings to other researchers to get feedback and subsequently enhance the validity of our findings.

\section{Findings}

After analyzing the data, we identified 8 main activities that contribute to the four main objectives of organizing. The category design by the architect and co-specialization by participants achieved task division. Agent that ise assigned to certain tasks or categories can be considered project leaders, or board managers in an open community. In ZGC, we call them "captain". The captain assignment by the architect and self-selection based on competition achieved task allocation. The value co-creation and entrepreneurial culture as a toolkit achieved reward distribution. Physical collocation plus virtual tools supporting intensive conferences achieved information flow (Fig. 2).

\section{Task division}

In ZGC, task division is accomplished through (1) the category design by the architect and (2) co-specialization by participants.

Task division comprises both centralized and de-centralized activities. High centralization of task division means that the power of dividing the tasks is centralized to a small group people. Otherwise, it spreads to everyone. An open community is considered an

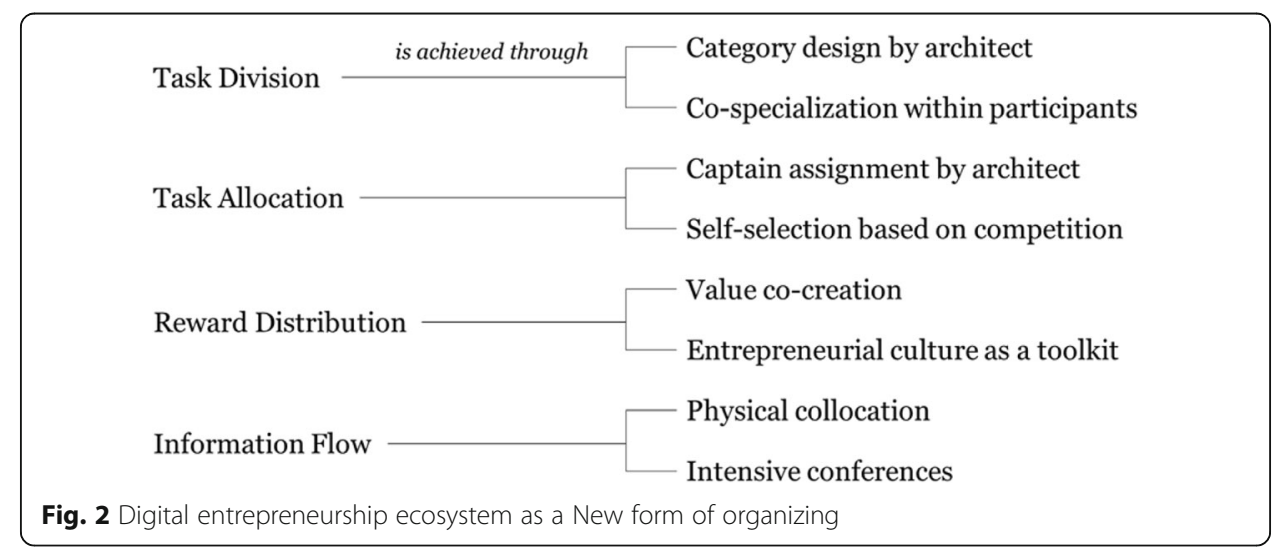


organization with low levels of centralization. Somehow, the initial design process of an open community also influences task division, which is decided by a small group of people.

In the early stages of ZGC, tasks were designed by the architect. This is considered a highly centralized approach (Gulati et al., 2012). When designing the digital entrepreneurship ecosystem, a system-level goal is essential. Task division needs to support this goal. The government, as the architect of ZGC, after studying the experiences of Silicon Valley, imitated the structure of Silicon Valley. Thus, main categories of tasks were designed such as acceleration centers, venture capital, entrepreneurial mentors, education resources and physical infrastructure, including collocation places, telecommunication facilities, transportation infrastructure and security protection. As an officer who participated in the designing process of ZGC stated: "In the initial stage of this project, we designed the main structure of ZGC, in which some specific members are necessary, such as acceleration centers, venture capital, collocation places and so on."

This highly-centralized process of design decides what kinds of work ZGC as a DEE provides. The visibility of the system goal and category makes it possible to attract agents who have the ability to achieve the system goal (Baldwin and Clark, 2006). To some extent, irrelevant members are excluded through the visibility and definition of the categories of organizations present in ZGC. For example, agents who aim to work for digital entrepreneurs would be attracted by the visible goal, while others unrelated to digital entrepreneurship would be excluded, such as the book store owners and the electronics merchants.

Although the architect can design the main task categories in the early stages, the details of subtask division in ZGC still needed to be explored. "Although we have experience with entrepreneurial services in Silicon Valley, the detailed structure of the entrepreneurship system still needed to be explored. Meanwhile, because the context of ZGC is quite different from Silicon Valley, we cannot copy the format of Silicon Valley directly", an officer participating the design of ZGC stated. But with more and more participation and contributions, task division can be elaborated and developed by itself (Puranam et al., 2014). Therefore, after designing the main tasks categories, the architect imported heterogeneous agents into ZGC through reward distributions such as subsidies to enable the complementariness of task division (Thomas and Autio, 2012). Therefore, at the subtask level, tasks are divided by self-organizing agents.

At this stage, heterogeneous agents with specialized resources and abilities cooperate and this cooperation overcomes the limited resources of individuals. These subtasks are not designed by the architect. For instance, some agents found that some entrepreneurs had problems converting innovative ideas into a business, and thus they established a consulting company to address this issue. In this case, these agents have specific experience and the ability to solve this problem, but they lack innovative ideas, while entrepreneurs have innovative ideas but lack the ability to achieve them. Therefore, co-specialization by participants gives rise to subtasks which are not designed by the architect. These subtasks enhance the completeness of task division.

\section{Task allocation}

The pattern of task allocation is close to that of task division because it has to solve the allocation problems based on task division (Puranam et al., 2014). In the early stage of ZGC, category design was the main method of task division. Correspondingly, methods 
of task allocation should suit the design process, as does the co-specialization process. In the case of ZGC, we found that task allocation is accomplished through (1) captain assignment by the architect and (2) self-selection based on competition, which corresponds to the methods of task division.

Assignment is a common method of task allocation in a highly-centralized process (Puranam et al., 2014). Under the assignment process, members are usually assigned to positions or subtasks that match their skills and profiles. In the early stage of development of ZGC, tasks were assigned to the members who owned adequate and appropriate resources to achieve the tasks.

Agents that are assigned to certain tasks or categories can be considered project leaders, or board managers in an open community. In ZGC, we call them "captains". Because these captains have premium resources and social reputations, they can create their own authority and manage this category well to support the system-level goal. For instance, a big IT company in China is assigned to be the captain of the category of hardware-related entrepreneurship. This company leverages both internal and external resources to build an environment that facilitates hardware-related innovation and entrepreneurship activities. These innovations and entrepreneurship activities are also beneficial for this company because they are related to the industry of this company and enhance the agility of the company through accessible innovation from outside. As we can see, these captains can manage their category well and benefit with the development of category (which solves the motivation problem). This highly-centralized process of assignment ensures the main tasks (or categories) be allocated to the right agent to achieve them.

Therefore, task allocation is achieved through captain assignment by the architect.

In the second phase, when captains have been confirmed, self-selection becomes the dominating approach toward task allocation. Self-selection is based on the task division of co-specialization, which is a process with low levels of centralization. Heterogeneous agents cooperate to achieve co-specialization based on their own inclinations, in which other highly-centralized allocation processes (such as assignment) are not involved. Meanwhile, for the self-organizing nature of ecosystem (Moore 1993), the main approach of task allocation in ZGC as a DEE is self-selection (Gulati et al., 2012; Puranam et al., 2014). As one entrepreneur stated: "Most service providers in ZGC are open to everyone, and we can choose them based on our interests. To the contrary, these service providers also have the right to choose you based on their interests."

However, when many resources flow into the DEE, redundant resources emerge since many agents have the same specialized capabilities. In these circumstances, competition among these redundant resources becomes inevitable. Only the fittest would survive under the mechanism of competition, which ensures the survival of premium resources and reduces the degree of redundancy. Competition also pushes the development of resources, such as improving service quality and cutting down costs. For example, many entrepreneurs have a demand for legal services. Some companies observed this demand and started to provide legal services specific to entrepreneurs. While choosing the service providers, entrepreneurs would compare them in terms of service quality and cost and then choose the best one. Likewise, service providers would improve service quality or cut down costs in order to survive in this market.

Therefore, task allocation is achieved through self-selection based on competition (Table 3). 


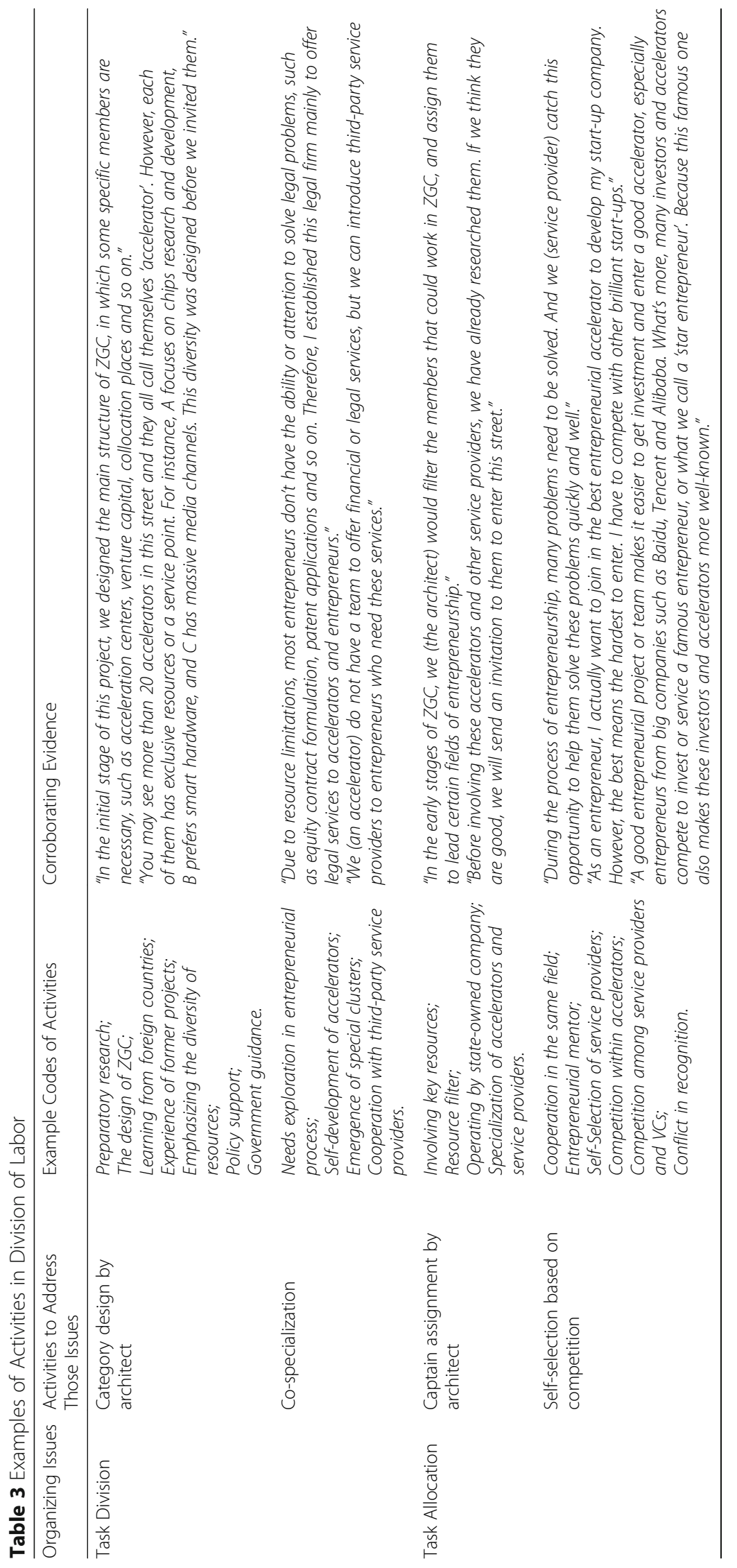




\section{Reward distribution}

Reward distribution solves the problem of creating motivation to join in the system and to make efforts to achieve the tasks. In ZGC's case, the motivation problem is achieved through (1) value co-creation and (2) entrepreneurial culture as a toolkit.

In virtual communities, such as Wikipedia and Linux, where tangible rewards (such as compensation and subsidies) are limited and the effort members contribute is almost all based on their personal preferences and interests, intrinsic motivation is considered the key factor to incentivize members to join in and expend effort (Gulati et al., 2012; Spigel, 2015). Yet, tangible rewards still work in many physical communities (Puranam et al., 2014). Many tangible rewards attract agents to join ZGC, such as subsidies from the government, low rents and other policies. These tangible rewards may have positive effects on attracting members, but we found in our investigation, these tangible rewards are not the main reason why people are attracted to ZGC. As an entrepreneur who is an overseas returnee stated: "Subsidies in ZGC are not so attractive to entrepreneurs because many other places could provide the same, or even better rewards. Policies about entrepreneurship are much more complex than in some foreign countries."

Many agents come to ZGC mainly for the commercial opportunities, while policies and subsidies are also a key decision-making factor. Opportunities come from the process of this system in which value can be captured and created by participants (Thomas and Autio, 2012). Since the resources and capabilities of individuals are limited, many agents join in the ecosystem to seek partners to cooperate to capture and create value. Thus it is a process of value co-creation. For instance, some legal service providers capture the value of legal services in the entrepreneurship process, and they cooperate with other service providers such as accelerators and collocation places to create value through solving the legal problems of entrepreneurs. The value co-creation also occurs at the individual-level, which is attractive to digital entrepreneurs. Many entrepreneurs come to ZGC for information exchange and contestation of innovation ideas. During the process of exchanging and contestation, the ideas are further shaped.

Value co-creation is a reward for agents who participate in the ecosystem. This reward is distributed through the mechanism of pay-by-effort, which is like the mechanism of an open market. Thus this distribution process is fair and the problem of free-riding which is one of the main concerns of an open community (Puranam et al., 2014) does not exist. At least in the ZGC case, no evidence of free-riding is found. As to the concern of ideas being stolen, few entrepreneurs worry about it, since they believe that they have the unique resources needed to achieve their ideas. As one entrepreneur explained: "I never worry about the issue of ideas being stolen, because I have unique resources to achieve my idea which others cannot copy. In contrast, I will be glad if my idea is copied by others. It means that my idea is valuable and worthy to be achieved."

The other factor that enhances reward distribution is a supportive culture. Culture provides a repertoire of shaping actions, just like a "tool kit" in which habits, skills and styles construct the action strategies (Swidler, 1986), and culture can also enhance other attributes of an ecosystem (Spigel, 2015). In the ZGC case, we find that culture supports and normalizes entrepreneurial activities, and ensures the fair distribution of rewards.

The supporting and normalization of entrepreneurial activities are a great motivation for entrepreneur participation. Because this culture supports risk taking and provides entrepreneurs and other agents with social support, it enhances their legitimacy in society. 
One entrepreneur who is not from Beijing, said: "In my hometown, people consider entrepreneurship a bad job. But the situation is totally different in ZGC, because it is the hometown of entrepreneurship."

Culture also ensures the fair distribution of rewards through the establishment of social norms (Shah, 2006). Social norms both encourage value co-creation and protect members from cheating or free-riding. As we discussed in the value co-creation part, there is a risk of cheating and free-riding, in which the mechanism of the commercial market may not be helpful. In this situation, social norms provide a way to constrain cheating and free-riding (Puranam et al., 2014). In ZGC, people consider themselves part of the internet generation, in which people take pride in sharing and cheating or free-riding is seriously dishonorable. This social norm protects them and encourages people to share their ideas and to achieve value co-creation and digital innovation.

\section{Information flow}

Information flow is accomplished through (1) physical collocation plus virtual supporting tools and (2) intensive conferences.

Information flow is common in physical collocation and grouping. It is also a basic way of coordination (Puranam et al., 2014). In ZGC, physical collocation and grouping are accomplished through geographical proximity. Members of ZGC are on the same street. This geographical proximity allows them to exchange information conveniently. For example, company A, which provides promotion services, and its neighbor, company B, which provides acceleration services, can coordinate effectively.

The traditional view holds that resource similarities lead to competition. However, in ZGC, resource similarities bring about cooperation. This kind of cooperation mainly occurs among small entrepreneurial teams, because many similar entrepreneurial teams work together in the same accelerator. For instance, in a software entrepreneurship accelerator, similar work talent or human capability can be shared among these entrepreneurial teams.

Virtual support infrastructure and tools include group chatting software, website platforms, mobile phone applications and so on. With the rapid development of mobile networks in China, it is very convenient to communicate through smart phones. In ZGC, an Instant Messaging application named WeChat is widely used. It supports group chatting so that information can flow broadly and quickly. Some service providers establish chatrooms on WeChat to connect entrepreneurs, service providers and investors. For example, one service provider in ZGC established a WeChat platform, on which entrepreneurs can upload their business plans and solicit expert feedback about the business plan and potential investment. The virtual support infrastructure and tools facilitate the flow of information, and enable coordination to occur beyond geographic limitations.

Besides common physical collocation and virtual supporting tools, the presence of conferences also plays a significant role in information flow. Conferences provide venues for the interaction of actors, exchanges of information and of different opinions (Garud, 2008). In ZGC, for various participants within the DEE and with the existence of heterogeneous fields, intensive conferences connect people and ensure the efforts from different participants can be integrated.

Per the official website of the ZGC DEE, since its establishment in June 2014, more than 2000 conferences have been held in ZGC. On the weekly ZGC notice board, there 
are, on average, 4 major conferences and several small gatherings a week, such as workshops, seminars and road shows. The intensive conferences create a wide information flow that enable deep coordination. For example, in elder-care technology seminars, much of the ground-breaking information in this field was shared, and the participants could better understand how they supported the development of this field (Table 4).

\section{Discussion}

This paper responds to the call for research on digital entrepreneurship (Shen et al. 2015) and entrepreneurship ecosystems (Autio et al., 2015). Using the case study of ZGC, we unveil a set of activities that influence the organization of DEEs (findings are summarized in Fig. 1).

The solutions of these four organizing problems (task division, task allocation, reward distribution and information flow) cannot be separated (Puranam et al., 2014). When the solution of one problem is decided, it can influence others and all the solutions must align. For example, self-selection-a common solution to task allocation in new forms-needs a lower degree of centralization in task division and tasks should be visible so that members can select themselves. Moreover, reward distribution and information must fit the pattern of self-selection. Each part of the problem has many different solutions, but not every solution suits the others. In this sense, when designing a digital entrepreneurship ecosystem, it is critical to understand what kinds of solutions are suitable. Our findings provide a set of solutions in the context of ZGC. It is not a general solution but it provides some implications and guidance to the designing and construction of digital entrepreneurship ecosystems.

The theoretical framework of forms of organizing provides an operational structure to analyze the digital entrepreneurship ecosystem. Our findings correspond to the four problems which are derived from the two universal problems of organizing, i.e. the division of labor and the integration of effort. However, these findings do not address the two universal problems directly. Hence we need to integrate these findings to correspond to the problems of division of labor and integration of effort. Our case analysis shows that the dynamic balance of centralization is important for the division of labor, and the supportive elements are critical to the integration of effort.

\section{The division of labor}

For ecosystems, low level of centralization is the key feature, because of their openness and self-organizing nature. However, centralization is not excluded from the ecosystem (Gulati et al., 2012). Some centralization is necessary for the establishment of the ecosystem. In the early stages in ZGC, task division was designed and task allocation was assigned, which is a highly centralized process. These highly centralized movements enhance the control of agents in the ecosystem. Through the category design, irrelevant members are excluded. Assignment ensures that tasks are allocated to agents with basic capabilities, and members without enough capabilities are excluded. Meanwhile, centralization ensures this ecosystem moves towards its goal, instead of evolving randomly. The categories are designed based on the system-level goal, which constrains the varieties of tasks that ZGC offers. The assignment ensures that members have the ability to manage the categories well and support the system-level goal. 


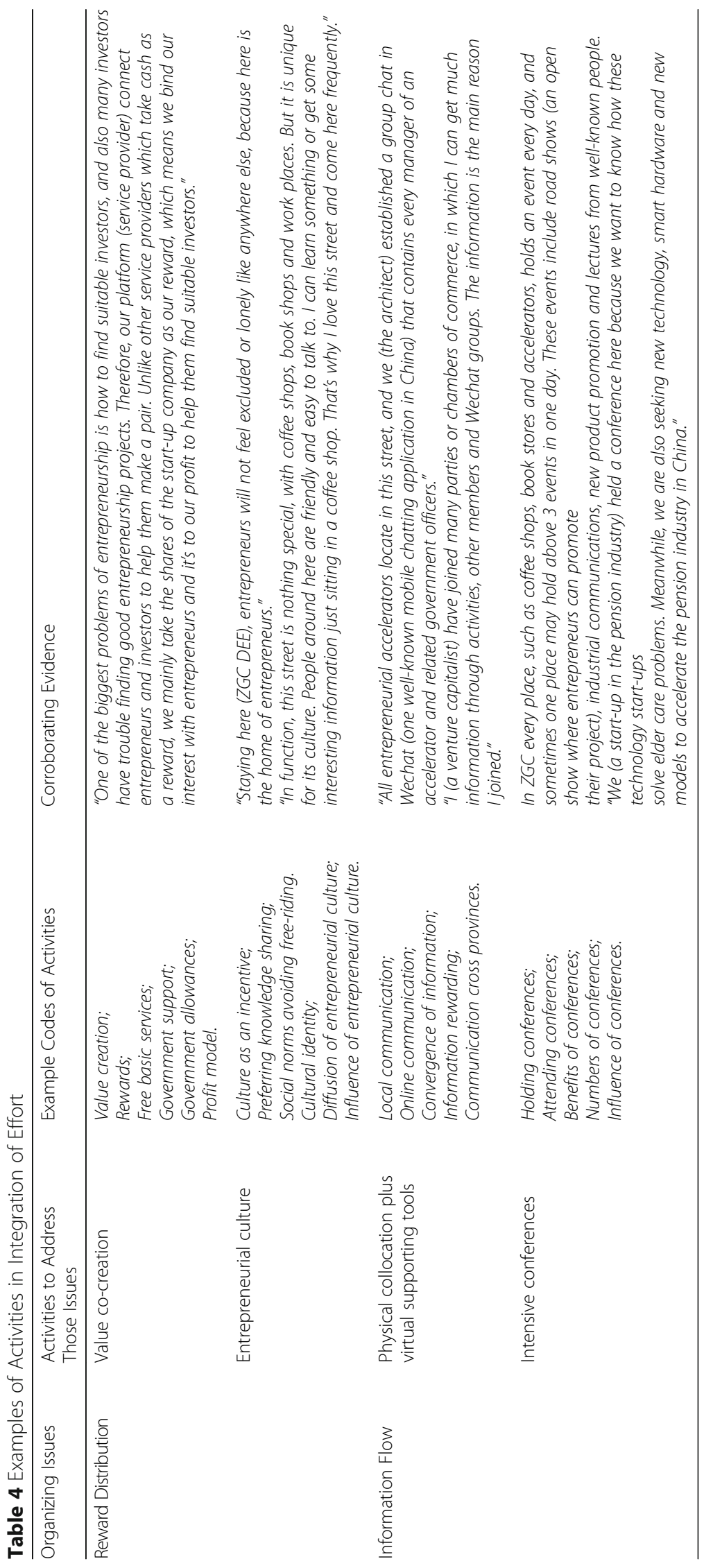


However, the ecosystem is too complex to be designed. Thus, bottom-up contributions address the weakness of a highly centralized process and complete the division of labor (Puranam et al., 2014; Thomas and Autio, 2012), such as subtask division through co-specialization and task allocation through self-selection.

In the current stage in the development of ZGC, low levels of centralization dominate the division of labor. While members contribute to the attainment of the system-level goal, complementariness of task division and the efficiency of task allocation have become the main needs. Therefore, low centralization dominates at this stage. However, that does not imply the disappearance of centralization at this stage. When the ecosystem does not function properly, for example, when reward distribution becomes unfair, the architect intervenes (Spigel, 2015).

Therefore, the division of labor in the ZGC case is a dynamic balance of high-level centralization and low-level centralization: in the early stage, a highly centralized process dominates and in the next stage, a process with low levels of centralization dominates.

\section{The integration of effort}

As to the integration of effort, the connection among agents within a DEE is important. Common methods used to advance integration in ZGC are value co-creation and physical and virtual collocation (Gulati et al., 2012; Puranam et al., 2014). Some connections are visible, while others are invisible and hard to capture. These invisible connections are similar to the routine details or hidden rules in an organization which are based on formal authority and hierarchy. In DEEs, they are more detailed and complex. We argue that enabling elements such as a supportive culture and intensive use of conferences enhance these connections and therefore, achieve integration of effort.

Culture influences the actions of people (Swidler, 1986). Culture is a critical element in a DEE (Spigel, 2015). The effect of an entrepreneurial culture shapes the actions of people within a DEE, and people sharing the same culture are connected to enforce the integration of effort. Agents in the DEE may not share the system-level goal, but they share the same culture, which is critical to shape the connection among these agents. Meanwhile, intensive conferences link numerous individuals and activities and have positive effects on the emergence of innovations in certain fields (Garud, 2008). Value co-creation and physical plus virtual collocation construct the main connection among agents, while a supportive culture and intensive conferences achieve connection so that the integration of effort is accomplished. Therefore, the supportive elements of culture and conferences are necessary for the integration of effort.

\section{Contributions and implications}

This paper has several theoretical contributions. First, our study contributes to the digital innovation literature by extending the scope of research on digital innovation to the ecosystem level. Most studies on digital innovation focus on the individual, organizational and industrial levels (Bharadwaj et al., 2013; Sambamurthy et al., 2003; Yoo et al., 2010;). Little is known about the ecosystem for digital innovations. Our study fills this research gap by studying DEEs from the perspective of forms of organizing, which provides our analytical framework. 
Second, our paper complements the study of organizational design by examining new forms of organizing a DEE. In organizational design studies, the collaboration among legally autonomous actors challenges traditional thinking about organizational design, because these actors collaborate effectively without traditional organizing elements such as formal authority and incentives (Gulati et al., 2012). To overcome these challenges, this kind of collaboration is considered to be a new form of organizing (Gulati et al., 2012; Puranam et al., 2014). One research question that is worth exploring is how the designers of these new organizing forms divide labor and integrate efforts (Gulati et al., 2012, p. 580). Our study answers that question. Moreover, the existing four-dimension theoretical framework takes an either/or perspective in choosing between emergent and top-down organizing. Our findings on digital entrepreneurship ecosystems demonstrate that these two approaches are not contradictory and can coexist.

Third, our paper also contributes to the entrepreneurship literature by unveiling the organizing process of an entrepreneurial ecosystem. Digital entrepreneurship ecosystems are not only ecosystems that generate digital innovations, but also ecosystems that support entrepreneurship based on digital innovations. Because of the lack of research on entrepreneurial ecosystems, the Strategic Entrepreneurship Journal (SEJ, a top journal in the field of entrepreneurship) called for papers on entrepreneurial ecosystems (Autio et al., 2015). Therefore, our paper responds to this research call by analyzing digital entrepreneurship ecosystems.

Our findings also have practical implications. As the establishment of DEEs is attracting more and more attention from practitioners, this paper may provide useful guidelines to architects and policy makers who intend to establish DEEs to support economic development. The theoretical framework of forms of organizing (task division, task allocation, reward distribution and information flow) provides a powerful instrument to both researchers and practitioners to better understand the forms of DEE organizing. As for members of a DEE, our findings enable them to better understand the organizing principles of a DEE for better involvement in a DEE.

\section{Limitation and future research}

This paper has several limitations. First, although we try to make our findings as inclusive as possible, we must acknowledge that it is hard to completely identify all the possible activities which compose the new forms of organizing within a DEE. It is hard to identify all of the large number of agents and activities within a DEE. Thus we try to capture the core activities that mainly impact the organizing process. Moreover, our single-case study on ZGC also causes limitation considering that different DEEs have different contexts. Therefore, future studies can focus on multiple cases in different contexts and apply the framework of forms of organizing to analyze other DEEs.

Second, the environment of ZGC as a DEE is relatively special because China's government and state-owned enterprises play an important role in its design and development. However, in other regions, such as Silicon Valley and India, the involvement of government in DEE creation and expansion is less than that in the Chinese context (Saxenian, 2004). This difference may produce different organizing forms, and some new organizing forms may be identified in different contexts. Because a 
DEE best practice does not currently exist, different designers have their own methods to explore the forms of organizing. Future studies can focus on DEEs in other regions which are quite different from China, and focus on the comparison of DEEs in different environments.

\section{Conclusion}

Collective collaboration has positive effects on digital innovation due to the combination of heterogeneous resources. This highlights the importance of digital entrepreneurship ecosystems (DEEs) for digital innovation because DEEs contains diversified resources and provide a platform for boundary-spanning practices. However, the understanding of DEEs is still limited (Spigel, 2015). From our observations, we argue that a DEE is not only a combination of resources (Spigel, 2015), but also a new form of organizing (Gulati et al., 2012; Puranam et al., 2014). In order to achieve the systemlevel goal, a DEE has to organize resources efficiently and effectively.

Through this case study, we unveil 8 activities which compose the organizing form of a DEE. These activities give us some insight about the balance of centralized design and decentralized emergence, which extends the existing studies on forms of organization that mainly take an either/or perspective. Our findings deepen our understanding of DEEs and provide practical guidelines for the development of DEEs.

\section{Appendix 1}

Table 5 Archival data

\begin{tabular}{|c|c|}
\hline Category & Examples \\
\hline $\begin{array}{l}\text { Government/Official } \\
\text { information }\end{array}$ & $\begin{array}{l}\text { - ZGC Innovation Way Official Website. Introduction: http://www.z-innoway.com/ } \\
\text { index.php?app=web\&m=Article\&a=detail\&id=16 } \\
\text { - Beijing Government Official Website (2015, } 12 \text { Oct). "Advanced Innovation Way" } \\
\text { expending } 7.2 \text { kilometers. Retrieved } 15 \text { Jan, } 2016 \text { from http://www.beijing.gov.cn/tzbj/ } \\
\text { tzxx/kfqdt/t1405612.htm } \\
\text { - Ministry of Science and Technology of the People's Republic of China (2014, } 18 \text { June). } \\
\text { The opening of ZGC Innovation Way. Retrieved } 15 \text { Jan, } 2016 \text { from http:// } \\
\text { www.most.gov.cn/kjbgz/201406/t20140617_113821.htm } \\
\text { - Zhongguancun Science Park: introduction to the "Golden Seeds Project". Retrieved } 15 \\
\text { Jan, } 2016 \text { from http://www.zgc.gov.cn/kjzzcx1/jzzgc/76822.htm }\end{array}$ \\
\hline News/Reporting & $\begin{array}{l}\text { - China Daily (2014, 13, June). Beijing Zhongguancun opens innovation street. Retrieved } \\
15 \text { Jan, } 2016 \text { from http://www.chinadaily.com.cn/beijing/2014-06/13/ } \\
\text { content_17584416.htm } \\
\text { - Xinhua Net (2015, 20, Mar). Beijing's Zhongguancun Innovation Street services for } \\
\text { startups. Retrieved } 15 \text { Jan, } 2016 \text { from http://news.xinhuanet.com/english/photo/2015-03/ } \\
\text { 20/c_134082125.htm } \\
\text { - People.cn (2015, } 7 \text { May). Premier of China Mr. Li is present at ZGC Innovation Way: Some } \\
\text { details you don't know. Retrieved } 15 \text { Jan, } 2016 \text { from http://politics.people.com.cn/n/ } \\
\text { 2015/0507/c1024-26965741.html } \\
\text { - People.cn (2015, } 30 \text { July). The number of startups incubated in ZGC is nearly 600. } \\
\text { Retrieved } 15 \text { Jan, } 2016 \text { from http://it.people.com.cn/n/2015/0730/c1009-27383824.html }\end{array}$ \\
\hline Videos & $\begin{array}{l}\text { - CCTV.com (2015, } 24 \text { May). Dialogue: the sequel to ZGC Innovation Way. Retrieved } 15 \\
\text { Jan, } 2016 \text { from http://jingji.cntv.cn/2015/05/24/VIDE1432481428440900.shtml } \\
\text { - Guangming TV (2015, } 19 \text { Oct). The disappearance of ZGC! Upgrading from electronics } \\
\text { market to innovation and entrepreneurship street. Retrieved } 15 \text { Jan, } 2016 \text { from http:// } \\
\text { www.iqiyi.com/v_19rrkydafo.html } \\
\text { - CCTV.com (2015, } 7 \text { May). Premier of China Mr. Li is present at the Chinese Academy of } \\
\text { Sciences and ZGC Innovation Way. Retrieved } 15 \text { Jan, } 2016 \text { from http://news.cntv.cn/ } \\
\text { 2015/05/07NIDE1430997481826462.shtml } \\
\text { - Reporter Association of China (2015, } 10 \text { June). Opening of ZGC Innovation Way, and } \\
\text { birth of the first entrepreneurship ecosystem in China. Retrieved } 15 \text { Jan, } 2016 \text { from } \\
\text { http://news.xinhuanet.com/zgjx/2015-06/10/C_134314277.htm }\end{array}$ \\
\hline
\end{tabular}




\section{Appendix 2}

Table 6 List of interviewees

\begin{tabular}{|c|c|}
\hline $\begin{array}{l}\text { Categories (Number } \\
\text { of interviewees) }\end{array}$ & Examples \\
\hline $\begin{array}{l}\text { Entrepreneurs } \\
(N=16)\end{array}$ & $\begin{array}{l}\text { - Mr. Yang, founder of an entrepreneurial Internet education company, former employee } \\
\text { of Midea (a large appliance company in China); } \\
\text { - Mr. Zhou, a college student preparing to set up their own company; } \\
\text { - Mr. Chen, founder of an Internet medical care entrepreneurial company, owns a successfully } \\
\text { IT company which is still running; } \\
\text { - Mr. Xu, founder of an entrepreneurial Internet catering company, a former employee } \\
\text { of Baidu (one of China's largest IT companies); }\end{array}$ \\
\hline $\begin{array}{l}\text { Government/State- } \\
\text { owned Enterprises } \\
(\mathrm{N}=8)\end{array}$ & $\begin{array}{l}\text { - One high-level officer and one operating officer with the Senior Services Informatics } \\
\text { Development Committee (SSIDC), a facility of the China Association of Social Welfare. } \\
\text { It was founded to improve innovation and development in senior care information; } \\
\text { - } 2 \text { mid-level officers with Haizhi Kechuang (HZKC), an institutional state holding company } \\
\text { that designed the ZGC innovation street and maintains it; } \\
\text { - } 3 \text { mid-level officers with Zhongguancun Administrative Committee (ZAC), a government } \\
\text { agency that guides the development and construction of ZGC; } \\
\text { - One mid-level with Beijing Municipal S\&T Finance Promotion Association, a government } \\
\text { agency promoting technology investment and providing financial advice; }\end{array}$ \\
\hline $\begin{array}{l}\text { Accelerator Centers } \\
(N=10)\end{array}$ & $\begin{array}{l}\text { - Founder, co-founders and main officials with Asia America Multi-Technology Association } \\
\text { (AAMA), an association focusing on accelerating technical startups. AAMA established its } \\
\text { angel fund in } 2012 \text { and set up an accelerator and coffee shop in } 2014 \text { in ZGC; } \\
\text { - Operating manager with Legend Star, providing entrepreneurial services such as mentorships, } \\
\text { acceleration and angel investment; } \\
\text { - Operating officer and coffee shop manager with } 3 \text { W coffee shop, a company that services } \\
\text { internet entrepreneurship and has its own coffee shop, accelerator, training program and } \\
\text { angel fund. }\end{array}$ \\
\hline $\begin{array}{l}\text { Third-party Service } \\
\text { Providers }(N=7)\end{array}$ & $\begin{array}{l}\text { - Financial advisor with Angel Service, a web platform connecting entrepreneurs and investors. } \\
\text { It also provides training to help entrepreneurs perform better when meeting with investors; } \\
\text { - Founder with Law Service, a company providing legal services to startups, such as company } \\
\text { registration, contract drafting, patent application and so on; } \\
\text { - Financial advisor with E-Capital, providing financial advice services for companies. }\end{array}$ \\
\hline Investors $(N=10)$ & $\begin{array}{l}\text { - Mr. Xie, co-founder with YCT, a venture capital investment company that focuses on catering, } \\
\text { cultural and technical industries. } \\
\text { - Mr. Guo, an angel investor who successfully set up XN Media; } \\
\text { - Mr. Zhang, Investment manager with Zhejiang PD Investment Company, a company located } \\
\text { in Zhejiang Province. }\end{array}$ \\
\hline
\end{tabular}

Total Number of Interviewees $N=51$

\section{Acknowledgements}

This research is supported by the Fundamental Research Funds for the Central Universities and the Research Funds of Renmin University of China (15XNF023). For helpful comments, we thank two anonymous referees, English editor in FBR, Meng Zhao, Xiaoyu Ji, Shan Wang, Ruidong Zhang and the 2016 Frontiers of Business Research in China International Symposium.

Authors' contribution

All authors read and approved the final manuscript.

\section{Competing interests}

The authors declare that they have no competing interests.

\section{Publisher's Note}

Springer Nature remains neutral with regard to jurisdictional claims in published maps and institutional affiliations.

Received: 14 April 2016 Accepted: 17 January 2017

Published online: 09 June 2017

\section{References}

Adner, R. \& Kapoor, R. (2010). Value creation in innovation ecosystems: how the structure of technological interdependence affects firm performance in new technology generations. Strategic Management Journal, 31(3), 306-333.

Autio, E., Nambisan, S., Wright, M., \& Thomas, L. D. (2015). Call for Papers for a Special Issue: Entrepreneurial ecosystems. Strategic Entrepreneurship Journal.

Baldwin, C. Y., \& Clark, K. B. (2006). The architecture of participation: Does code architecture mitigate free riding in the open source development model? Management Science, 52(7), 1116-1127. 
Bessant, J., \& Tidd, J. (2007). Innovation and Entrepreneurship. Chichester: John Wiley \& Sons.

Bharadwaj, A., El Sawy, O. A., Pavlou, P. A., \& Venkatraman, N. (2013). Digital business strategy: Toward a next generation of insights. MIS Quarterly, 37(2), 471-482.

Biao, \& Dong. (2014). Determinants of successful it-enabled business innovation: a case study from the perspective of institutional entrepreneurship theory. Frontiers of Business Research in China. 8(2):227-244.

Corallo, A., Passiante, G., \& Prencipe, A. (Eds.). (2007). The digital business ecosystem. Cheltenham: Edward Elgar Publishing.

Corbin, J., \& Strauss, A. (1990). Basics of qualitative research: Grounded theory procedures and techniques. Modern Language Journal, 77(2), 129.

Davidson, E., \& Vaast, E. (2010). Digital entrepreneurship and its sociomaterial enactment. 43rd Hawaii International Conference on System Sciences (HICSS) (pp. 1-10).

Eisenhardt, K. M. (1989). Building theories from case study research. Academy of Management Review, 14(4), 532-550.

Garud, R. (2008). Conferences as venues for the configuration of emerging organizational fields: The case of cochlear implants. Journal of Management Studies, 45(6), 1061-1088.

Gulati, R., Puranam, P., \& Tushman, M. (2012). Meta-organization design: Rethinking design in interorganizational and community contexts. Strategic Management Journal, 33(6), 571-586.

Hackman, J. R., \& Oldham, G. R. (1976). Motivation through the design of work: Test of a theory. Organizational Behavior and Human Performance, 16(2), 250-279.

Herrmann, B. L., Gauthier, J. F., Holtschke, D., Berman, R., \& Marmer, M. (2015). The global startup ecosystem ranking 2015. Available online at, https:/startup-ecosystem.compass.co/ser2015/, retrieved March 28, 2016.

Klein, H. K., \& Myers, M. D. (1999). A set of principles for conducting and evaluating interpretive field studies in information systems. MIS Quarterly, 23(1), 67-93.

Lindgren, R., Andersson, M., \& Henfridsson, O. (2008). Multi-contextuality in boundary-spanning practices. Information Systems Journal, 18(6), 641-661.

MacCormack, A., Rusnak, J., \& Baldwin, C. Y. (2006). Exploring the structure of complex software designs: An empirical study of open source and proprietary code. Management Science, 52(7), 1015-1030.

Moore, J. F. (1993). Predators and prey: A new ecology of competition. Harvard Business Review, 71(3), 75-83.

Peltoniemi, M., \& Vuori, E. (2004). Business ecosystem as the new approach to complex adaptive business environments in Proceedings of eBusiness research forum. Citeseer, 18, 267-281

Prendergast, C. (1999). The provision of incentives in firms. Journal of Economic Literature, 37(1), 7-63.

Puranam, P., Alexy, O., \& Reitzig, M. (2014). What's 'new' about new forms of organizing? Academy of Management Review, 39(2), 162-180.

Roth, E., Seong, J., \& Woetze, J. China's innovation imperative McKinsey \& Company. Available online at, http://www. mckinsey.com/business-functions/strategy-and-corporate-finance/our-insights/gauging-the-strength-of-chineseinnovation, retrieved March 28, 2016.

Sambamurthy, V., Bharadwaj, A., \& Grover, V. (2003). Shaping agility through digital options: reconceptualizing the role of information technology in contemporary firms. MIS Quarterly, 27(2), 237-263.

Saxenian, A. 2004. The Silicon Valley Connection: Transnational Networks and Regional Development in Taiwan, China and India, in India in the Global Software Industry A. P. D'Costa and E. Sridharan (eds.), Palgrave Macmillan UK, 164-192.

Schilling, M. A., \& Phelps, C. C. (2007). Interfirm collaboration networks: The impact of large-scale network structure on firm innovation. Management Science, 53(7), 1113-1126.

Selander, L., Henfridsson, O., \& Svahn, F. (2010). Transforming ecosystem relationships in digital innovation. ICIS, 2010, 138.

Shah, S. K. (2006). Motivation, governance, and the viability of hybrid forms in open source software development. Management Science, 52(7), 1000-1014.

Shane, S., \& Venkataraman, S. (2000). The promise of entrepreneurship as a field of research. Academy of Management Review, 25(1), 217-226

Shen, K., Lindsay, V., Xu, Y., \& Calvin. (2015). Information systems journal special issue on digital entrepreneurship. Information Systems Journal. http://onlinelibrary.wiley.com/store/10.1111/(ISSN)1365-2575/asset/homepages/ISJ_SI_ Digital_Entrepreneurship.pdf?v=1\&s=696d716f21e6137e1fbe32f3b0fd4afee81 c9618\&isAguDoi=false, retrieved February 5, 2017.

Siggelkow, N. (2007). Persuasion with case studies. Academy of Management Journal, 50(1), $20-24$.

Spigel, B. (2015). The relational organization of entrepreneurial ecosystems. Entrepreneurship Theory and Practice, 41(1), 49-72.

Swidler, A. (1986). Culture in action: Symbols and strategies. American Sociological Review, 51(2), 273-286.

Thomas, L., \& Autio, E. (2012). Modeling the ecosystem: a meta-synthesis of ecosystem and related literatures. In DRUID 2012 Conference, Copenhagen (Denmark).

Walsham, G. (1995). Interpretive case studies in IS research: Nature and method. European Journal of information Systems, 4(2), 74-81.

Yi, Z., Gu, D., Song, H., \& Yu, K. (2008). A technological innovation model based on resource integration. Frontiers of Business Research in China, 2(3), 397-416.

Yin, R. K. (2013). Case study research: Design and methods. London: Sage publications.

Yip, G. (2015). The 'three phases' of chinese innovation. Available online at, http://www.forbes.com/sites/ceibs/2015/03/ 23/the-three-phases-of-chinese-innovation/, retrieved March 28, 2016.

Yoo, Y., Henfridsson, O., \& Lyytinen, K. (2010). Research commentary-The new organizing logic of digital innovation: An agenda for information systems research. Information Systems Research, 21(4), 724-735.

Zahra, S. A., Wright, M., \& Abdelgawad, S. G. (2014). Contextualization and the advancement of entrepreneurship research. International Small Business Journal, 32(5), 479-500.

Zhang, S., Yi, X., \& Su, X. (2012). Rigor and relevance: on the development of entrepreneurship research in China. Frontiers of Business Research in China, 6(3), 418-434 